\title{
Division Technique Training Tool for Problem Solving Methods of IPR
}

\author{
Gil Su Yoon ${ }^{1}$, You Heon Kim², Sung Ju Lim ${ }^{1}$ \\ ${ }^{1}$ Pukyong National University, Interdisciplinary Program of Intellectual Property, \\ Graduate School, Pukyong National University, Busan, Korea \\ ${ }^{2}$ Korea Invention \& Promotion Association, Invention and Promotion Association, Korea \\ Email: gilsuyoon@gmail.com
}

Received 2012

\begin{abstract}
We have developed a training tool of division technique among 5 techniques in ASIT for problem solving method for Intellectual Property Right. Even though with its good capability, there were no applicable training tool to use for division training because of its easy disassembled shape with small disturbance. To develop a division technique training tool, we have applied ASIT to game T. We have chosen game shape parts with magnetic rubber and board as the plate coated with zinc. The adhesive strength of the game shape parts to board is enough to keep fixed position even in turn down. Developed tool is expected to use for the e-learning of problem solving training for student education and lifelong education. It is under Korean utility model application. E-learning with open resources including beneficial training for solving problem will develop together in foundation of life-long education. This division training device is proposed to younger generation as the educational auxiliary training tool for problem solving method. We have applied for Korean patent of the lifting method of methan hydrate which can be extended to various fields of IPR.
\end{abstract}

Keywords: Division Technique; ASIT; Training Tool; Problem Solving Method; Intellectual Property Right

\section{Problem Solving Methods}

We are making decisions every day from a mere trifle to important things. Making correct decision is quite important. Our future is full of vagueness which we don't know about. It is news to us at all. So we should not afraid of our failures. There is a proverb that "Failure is but the threshold of success." We should not afraid of failure in our youth days. We can experience indirectly by reading books and OCW resources et al. There are many techniques for solving problems. Especially 3 types of thinking method, Brainstorming, TRIZ and ASIT will be overviewed among them.

\section{Brainstorming}

Brainstorming is a usual group meeting technique designed to generate a large number of ideas for the solution to a problem. Osborn proposed that groups could double their creative output by using the method of brainstorming. Although brainstorming has become a popular group technique, researchers have generally failed to find evidence of its effectiveness for enhancing either quantity or quality of ideas generated (Brainstorming 2010). Well known international consultant company IDEO uses brainstorming method very well for developing new products (Ideo 2010). Thinkmap is a kind of program for brainstorming. When we concentrate on a specific topics, we are apt to effluent many things unrelated to the topic. It is not to be blamed and it is only natural for human who uses right and left cerebral simultaneously.

\section{TRIZ}

TRIZ is a romanized acronym for Russian "Teoriya Resheniya
Izobretatelskikh Zadatch" meaning "The theory of solving inventor's problems" or "The theory of inventor's problem solving”. It was developed by a Soviet engineer and researcher Genrich Altshuller and his colleagues starting in 1946. TRIZ, in contrast to techniques such as brainstorming which is based on random idea generation, aims to create an algorithmic approach to the invention of new systems, and problem solving as Figure 1 (TRIZ 2010).

Even though and LG and Samsung and many companies have developed new products with the application of TRIZ there are many tools such as contradiction matrix, Su-Field analysis, ARIZ (Algorithm for TRIZ), it needs much training and experiences to apply TRIZ to solve real problems.

\section{ASIT}

ASIT (Advanced Systematic Inventive Thinking), is a modified version of TRIZ by Israel prof. Roni Horowitz. He modified the complication of TRIZ into 5 simple methods such as

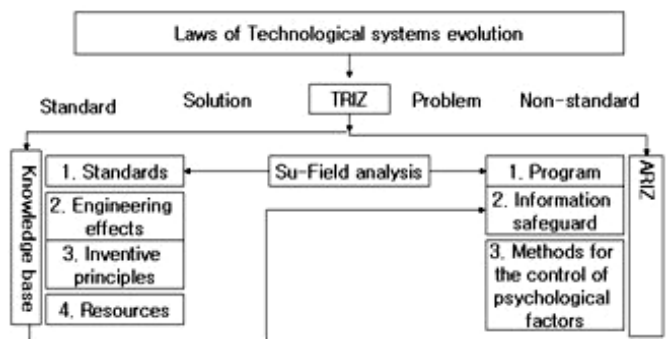

Figure 1.

Structural diagram of TRIZ (from Wikipedia). 
unification, multiplication, division, breaking symmetry and removal. Compared with other methods, ASIT is simple and easy to apply to solve real problems. TRIZ is more applicable to much complicated engineering problems, but ASIT is easier simple problem solver. Generally speaking compared with other methods, ASIT is a simple and easy to apply to solve real problems. To develop the ability of solving problems it is recommended to train division technique with appropriate training tools (Yoon, Kodama \& Park, 2008, Yoon, 2009).

\section{Problem Solving Process in ASIT}

ASIT uses 3 stages for 1) finding out problem objects and environmental objects 2) describing undesired effect and use for 5 technique templates 3) Elaborating the solution as Figure 2.

In ASIT it is important to find out problem objects and select proper one of 5 provoking techniques, which are unification, multiplication, division, breaking symmetry and removal. Each technique uses template to help to find agent for desired action mechanically. Functional fixedness interrupt us from creative thinking, so in problem solving process in ASIT, 3 stages with templates are used for mechanical process that we are easy to neglect in normal way of thinking. As in Figure 2 we find problem objects and environmental objects at the 1st stage. At 2nd stage we write down undesired effects. And write the desirable sentence from undesirable sentence. It is not easy to select a proper technique to solve problem. After selecting a proper technique we substitute automatically objects to that template. At 3rd stage we are elaborating the solution. There are 5 technique templates in Table 1 (Horowitz 2005).

\section{Division Technique}

Division technique is frequently used for ASIT solving problem among 5 techniques. The template of division technique is that the object $<>$ will be divided its part and will be reorganized in space and time. Let's play with the match game at first. A cow is chased from a lion. The lion can't catch the cow when cow see the lion. Moving with only 2 matches, how you save cow from lion's attack?

When asked with this problem, they seems to solve this problem like followings.

But this is not the same cow because of the tail position is changed to upward not in the middle of original position. So it is not correct answer. What is correct answer? We divide the head from the whole cow and turn to lion then the lion can't catch the cow. It is an example to be applied with a division technique. Cow's head part is divided from the cow's whole body and reorganized its shape in space. It is not included in time in this match game. The scope of division technique for problem solving is covered very much.

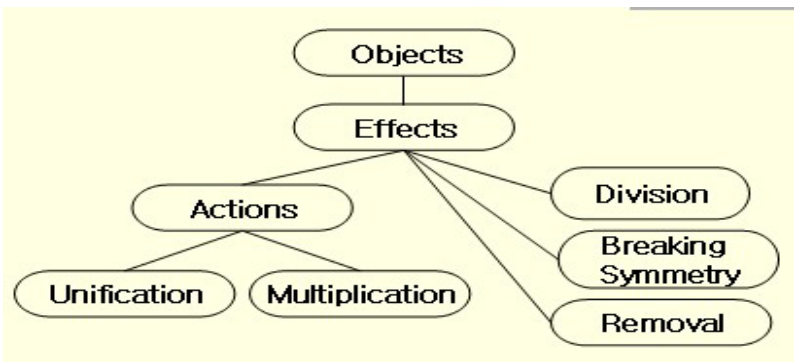

Figure 2.

ASIT 3 stages for solving process.
Table 1.

Five technique templates

\begin{tabular}{|c|c|}
\hline technique & template \\
\hline Unification & The object $<>$ will be the agent of the action $<>$. \\
\hline $\begin{array}{l}\text { Multiplica- } \\
\text { tion }\end{array}$ & $\begin{array}{l}\text { New object of the same type as }<>\text { will be the agent of } \\
\text { the action }<>\text {. }\end{array}$ \\
\hline Division & $\begin{array}{l}\text { The object }<>\text { will be divided its part and will be reor- } \\
\text { ganized in space and time. }\end{array}$ \\
\hline $\begin{array}{l}\text { Breaking } \\
\text { symmetry }\end{array}$ & $\begin{array}{l}\text { At different locations in }<> \\
\text { there will be a different value of the property }<>\text {. }\end{array}$ \\
\hline Removal & $\begin{array}{l}\text { The object }<>\text { will be removed from the problem } \\
\text { world. }\end{array}$ \\
\hline
\end{tabular}

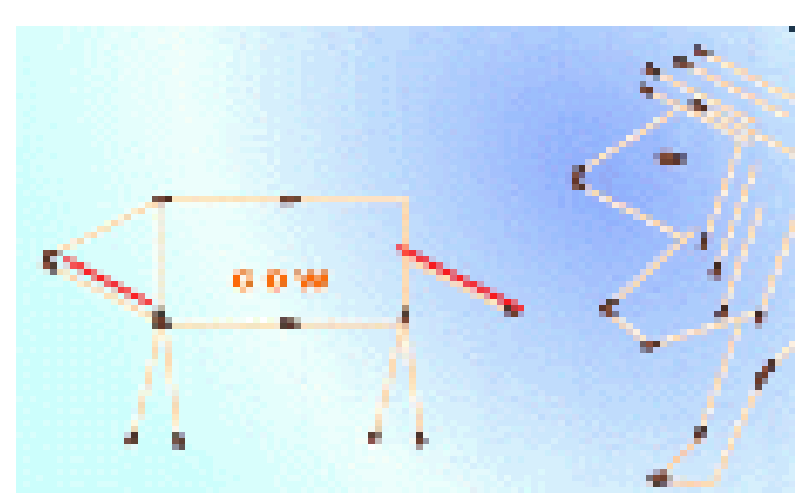

Figure 3.

A match game that a cow chased from a lion.

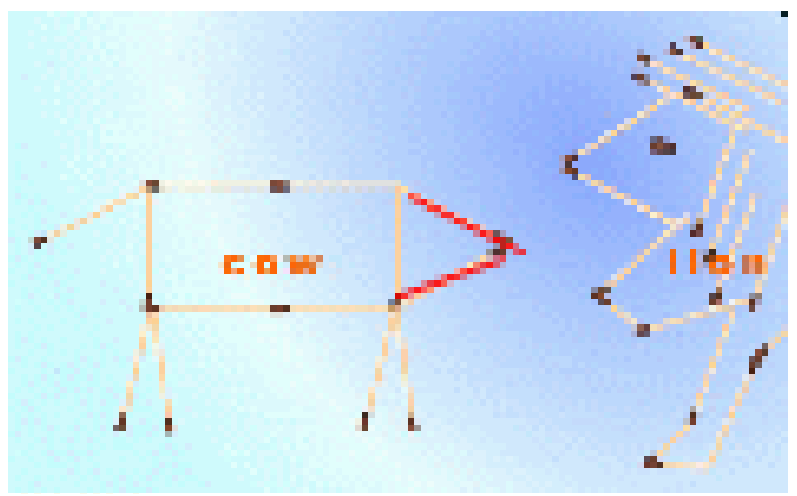

Figure 4.

Cow turns back to lion.

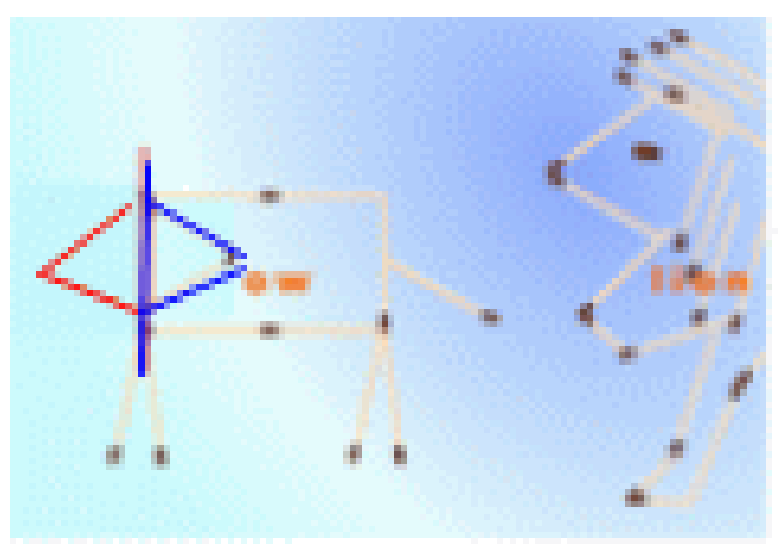

Figure 5.

Cow turns only its face to lion. 
Another fish saving game is rather related to the breaking symmetry technique not only division technique (Horowitz, 2007).

\section{Game T, Assembly Game}

Game $\mathrm{T}$ is an assembly game. Game $\mathrm{T}$ can be used as a practicing tool of division technique with 4 fixed shapes. Even though we can not make use of arbitrary shapes in game $\mathrm{T}$, it can be used for us as a good training tool for division technique to find out the prescribed shapes.

A house shape is composed with 4 fixed parts as Figure 6. It seems that we cannot fully practice for training to find out composed component parts, but it is easy that we can practice to find out how to assemble predefined shape. So we can make use of game $\mathrm{T}$ as a division training tool of ASIT. There are more than 20 shapes assembled with only 4 fixed component parts as seen in Figure 6 (Karin \& Kanel, 2008) .

For example situated at the right below inverse $\mathrm{z}$ shape is assembled with 4 component parts as in Figure 7.

\section{Division Technique Training Method}

There are long arrow shape and short plump arrow shape as Figure 8. It takes some time and it is not easy to assemble these two arrows continuously. It takes some time to find the assembled long shape and short plump arrow separately as in Figure 9. It is also not easy to assemble these two arrows continuously.
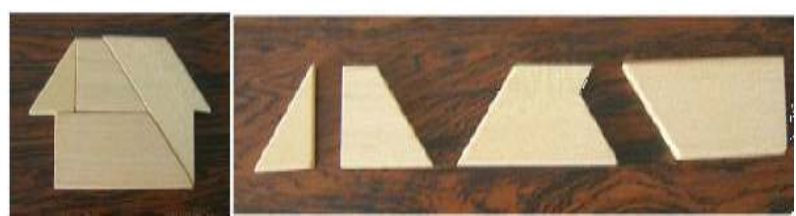

Figure 6.

Assembled shape with its 4 components.
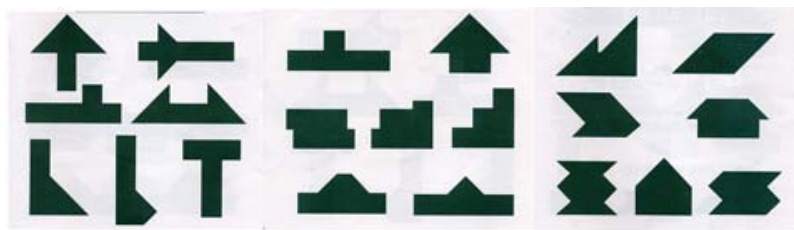

Figure 7.

Assembled shape with its 4 components.

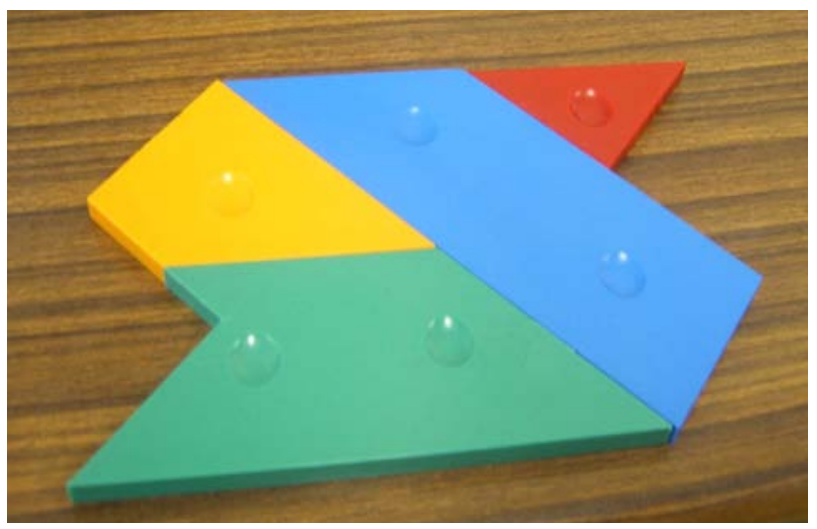

Figure 8.

Inverse $\mathrm{z}$ shape with its 4 components.

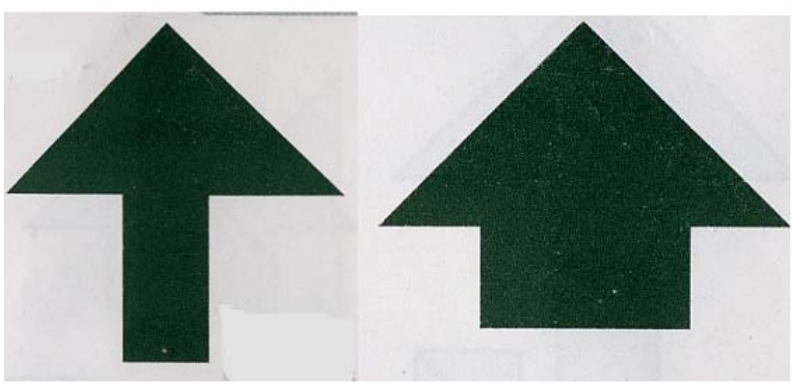

Figure 9.

Two arrow shapes.

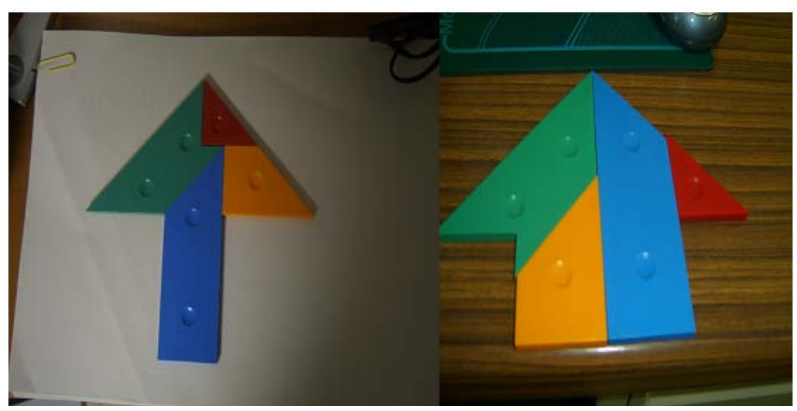

Figure 10.

Assembled shape of long arrow and short plump one.

There are vase shape and inverse $\mathrm{z}$ shape as Figure $\mathbf{1 1}$ and 12. These shapes are seemed to indifferent to short plump arrow shape.

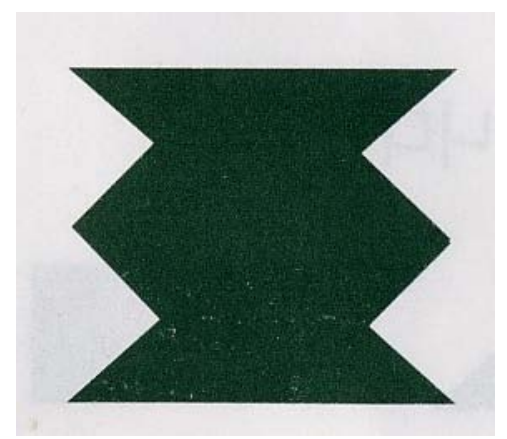

Figure 11.

Vase shape.

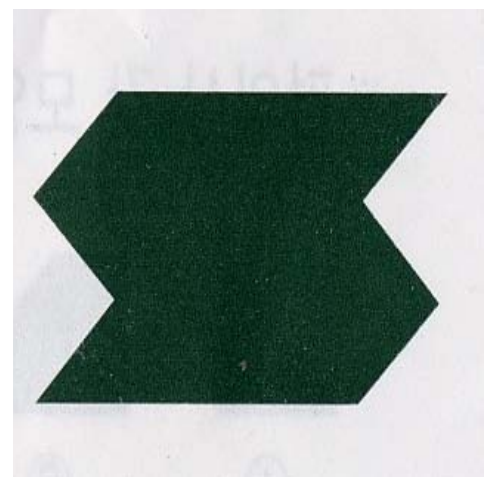

Figure 12.

Inverse $\mathrm{z}$ shape. 
But if you divide the inverse $\mathrm{z}$ shape with a line as Figure 12, you can get easily short plump arrow by up -side down left or right part as in Figure 13.

How can you get the pentagon shape as in Figure 14? There are various methods to make the pentagon shape as Figure 14. But you can get pentagon shape of Figure 14 with moving only one part from short plump arrow as in Figure 10.

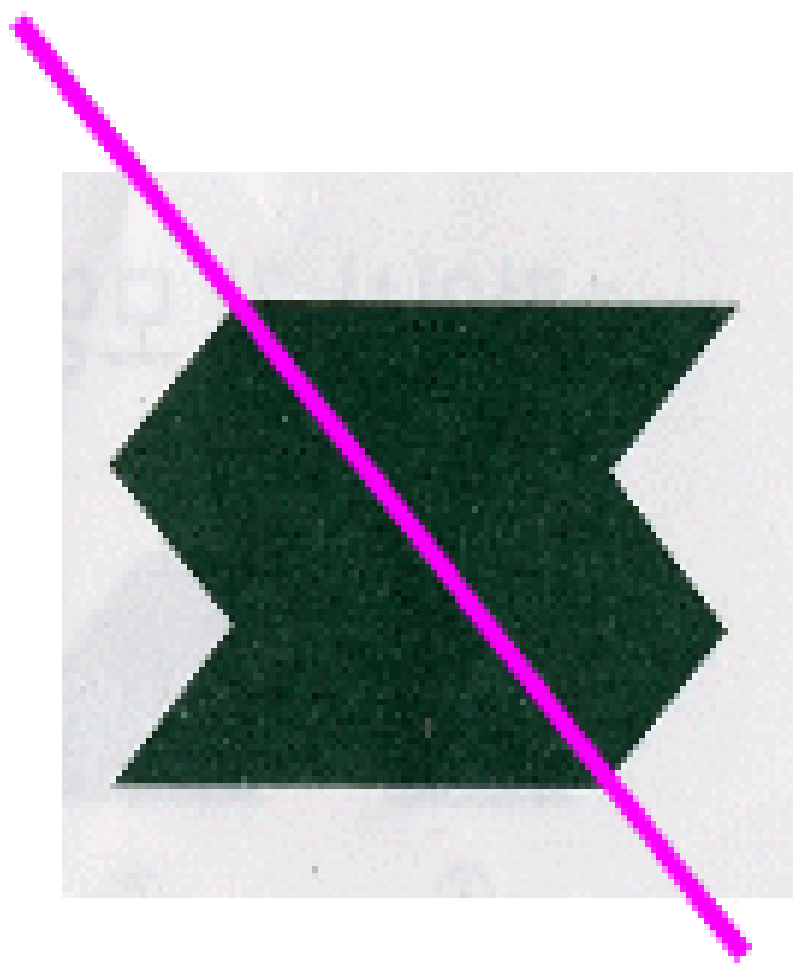

Figure 13.

Divide reverse $\mathrm{z}$ shape with a line.

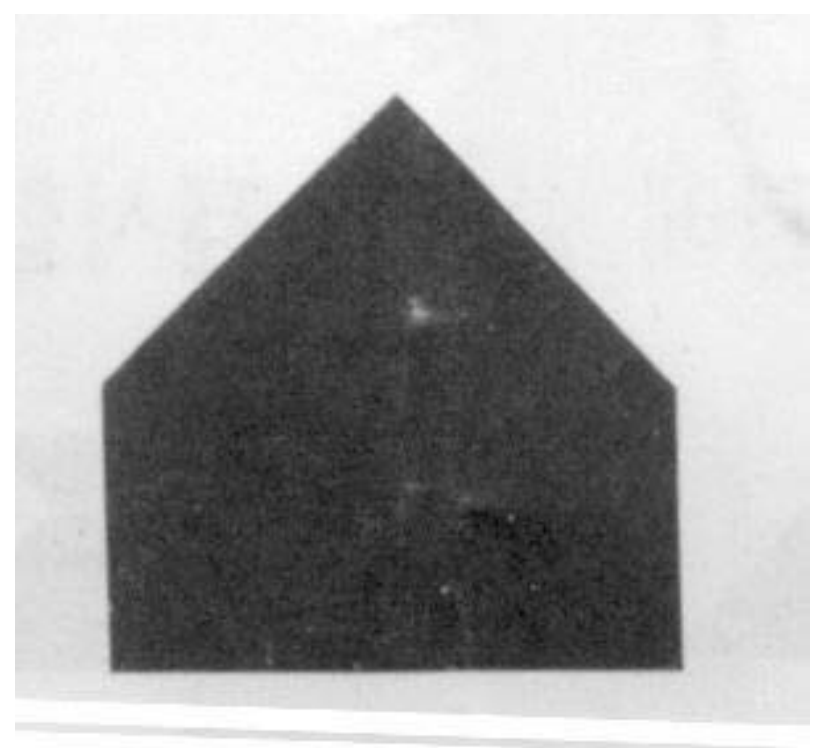

Figure 14.

Pentagon shape.

\section{Application of ASIT to Game T}

Electronic game installed in smart handheld phone is increasing in these days. But many electric games are biased with violence and erotic games which are not good for children. Conventional game such as game $\mathrm{T}$ needs consideration is rather better in the mental health for creative thinking than electronic games which stimulate one's nerves. Nevertheless game $\mathrm{T}$ is easily scattered and it is greatly bothered to play with for children. The game $\mathrm{T}$ is a good tool for training tool of division technique to students. But it is inconvenient to practice game T to play with parts on the desk. I have applied ASIT to game T to solve this problem. In 1st stage, the problem object is game parts. Undesired effect is game parts are easily scattered with small disturbance. In 2nd stage, desired effect is the game parts are fixed in their position. In 3rd stage, I select IFR instead of 5 techniques. IFR is to keep their position without any movement for any arbitrary posture. If I use magnetic rubber game parts, they can stick to their position. If I can try this game on the vertical board, it will be easy to show that to the students. So I applied IFR to the game T. IFR is to stick game shape parts to the board automatically. If I can make use of magnetic force it is possible for the shape parts to stick on the board. At 1st, I find out magnetic rubber. It can stick magnetic rubber parts on the magnetic rubber board, but it is easily rumpled as in Figure 16. But the magnetic rubber board is so weak that it is easily corrugated.

So we have tried to find stronger materials. At the end we find out a board as the plate coated with zinc. The adhesive strength of the game shape parts to board is enough to keep fixed position on board without scattering or falling down even in turn down position as Figure 13. It is now under Korean utility model. With this portable game we can practice division technique of ASIT as much as we likes. This can be used as the portable training tool of division technique among 5 techniques in ASIT for problem solving method. Developed tool is expected also to use for the e-learning of problem solving method or even to IPR (Intellectual Property Right) for the education of younger generation and lifelong study.

\section{Application ASIT to lifting method of Methane hydrate}

Conventional lifting method of methane hydrate was like Figure 17. We have applied ASIT to the lifting method of methane hydrate and we have registered Korean patent. At $1^{\text {st }}$ stage, we selected problem objects as rising pipe, methane hydrate and mother ship. And we selected waves and water depth as environmental objects.

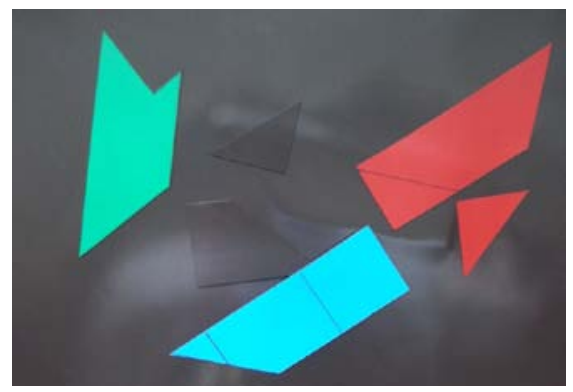

Figure 16.

Magnetic rubber board and parts 


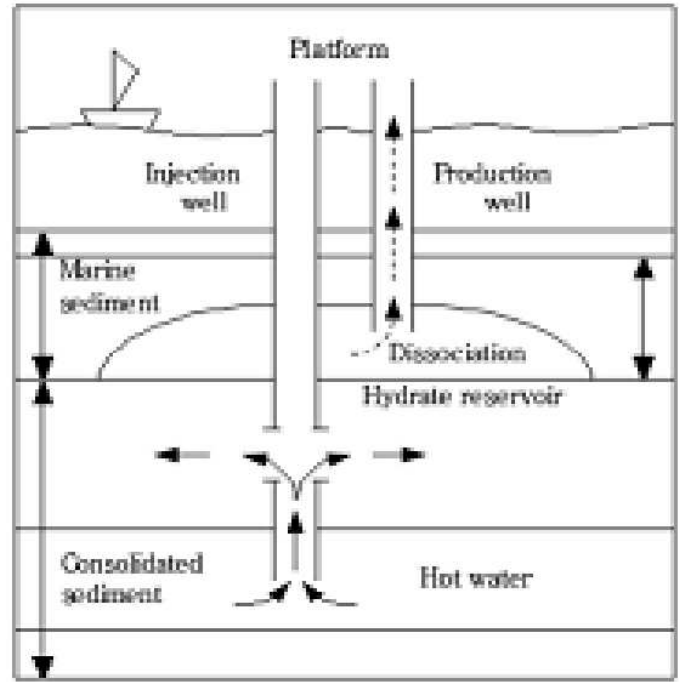

Figure 17.

Conventional lifting method of methane hydrate.

At $2^{\text {nd }}$ stage, we described undesirable effects as gas leakage of methane hydrate. From this we can describe desirable effect as lifting with ice shape of methane hydrate. At $3^{\text {rd }}$ stage we selected removal technique. Refrained a little from IFR with inter compressed container, we can remove rising pipe with inter compressed container with ice shape. We have developed a new lifting method of methane hydrate with inter compressed container as Figure 18.

We filed as 1020080051292 and registered for Korean patent as Figure 19.

We believe firmly that ASIT and its division technique training tool are applicable to find creative solution for some kind of solving problems. Why don't try this easy training tool to apply for your case?

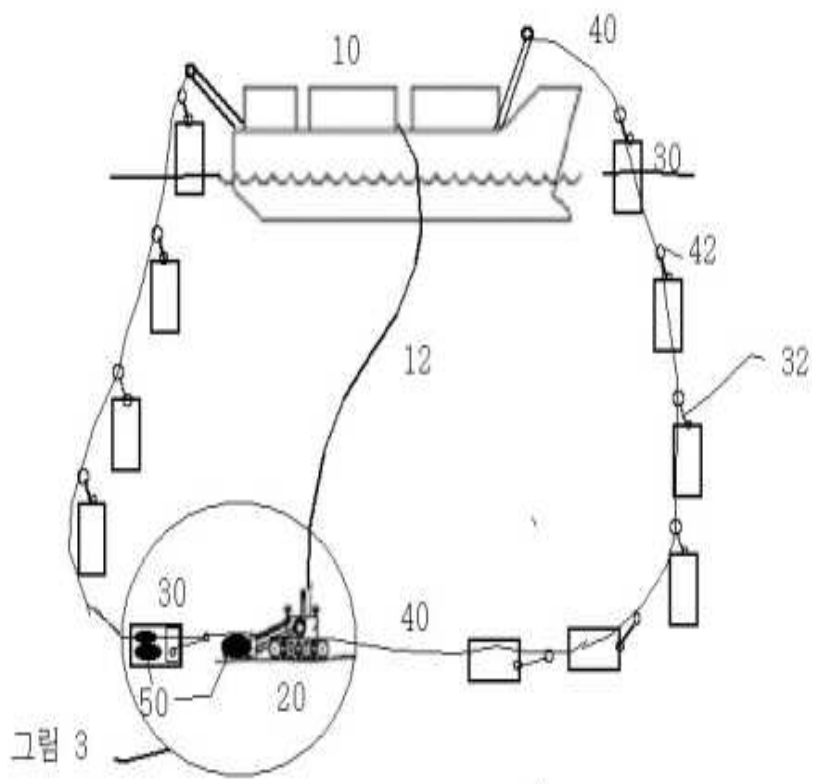

Figure 18.

New lifting method of methane hydrate.

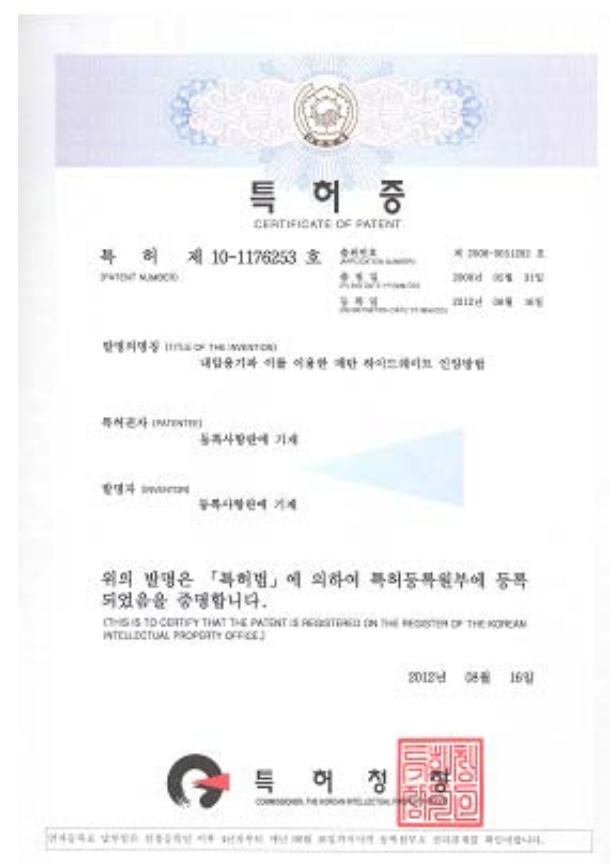

Figure 19.

Registered certificate of Korean patent.

\section{Conclusion}

This paper deals with the ASIT division technique for training of solving problems. Game $\mathrm{T}$ is a good training tool for solving problems. But it is inconvenient to practice on the desk. So Applied with IFR, ASIT to the game T, we found out a solution for board with zinc and magnetic rubber parts for division technique in any convenient posture. Some cases are shown for division technique training for children and students. As better achievement one gets, game $\mathrm{T}$ will be more difficult to find solution with black parts for tough training of division technique. We also applied ASIT to methane hydrate and we have registered Korean patent. We think it will be applicable from various games for younger generation as the education auxiliary tool such as ASIT division technique for problem solving to develop one's ability for Intellectual Property Right (IPR) by way of e-learning and lifelong education. We believe to add an interesting application case of ballast free ship problem with this division technique training tool the end of October, 2012. We would like to propose an international collaboration for various division technique training tool. We are cordially appreciated any questions or comments and proposal or suggestion for international cooperation.

\section{Acknowledgements}

Following are results of a study on the "Leaders Industry university Cooperation” Project, supported by the Ministry of Education, Science \& Technology (MEST), Korea.

\section{REFERENCES}

Horowitz R. (2005). Introduction to ASIT, private Adobe pdf file type e-book, p.42-94

Horowitz R. (2007). ASIT Premier, 


\section{G. S. YOON ET AL.}

http://Start2Think.com, http://www.start2think.com/indx.html

Karin \& J. V. Kanel. (2008). The T Puzzle,

http://www.woodpuzzles.com/Puzzles/T_Puzzle/T_Puzzle.html

Yoon, G. S., H. Kodama \& Y.W. Park. (2007). How to apply TRIZ to the e-learning from invent and patent to IP for SMEs, 3rd TRIZ International Symposium, Yokohama, Japan. pp.227-250.

Yoon, G.S., H. Kodama \& Y.W. Park. (2008). How to practice for the solving problems of invent, patent and IP education by way of e-learning, 3rd PAAMES /AMEC2008, Chiba, Japan, pp.801-812.

Yoon G. S. (2009). Invention and Patent,
http://www.kocw.net/home/search/kemView.do?kemId=127676, KOCW, (in Korean)

Yoon G. S. (2009). Necessity of education for Creative Problem Solving Method -Modified Lifting method for Methane Hydrate by ASIT-, 2009 KSOE joint symposium of Ocean Science. CECO, pp.1787-1790. (in Korean)

Lim S. J. \& Yoon G. S. (2011). Proposal for e-learning of division technique training tool for problem solving method, ASIT, The 2011 international symposium on advanced engineering of college of engineer-ing pukyong national university. 